\title{
ИННОВАЦИОННЫЕ ТЕХНОЛОГИИ В ОБРАЗОВАНИИ
}

УДК 37.047

DOI 10.23951/1609-624X-2021-5-105-115

\section{РЕАЛИЗАЦИЯ ПРОГРАММ ПОДГОТОВКИ К СОРЕВНОВАНИЯМ JUNIOR SKILLS: ОЧНАЯ И ДИСТАНЦИОННАЯ ФОРМА ОРГАНИЗАЦИИ}

\section{B. А. Борисова}

Национальный исследовательский Томский государственный университет, Томск

\begin{abstract}
Введение. Подготовка обучающихся к участию в соревновательных мероприятиях Junior Skills - актуальная задача современного образования. Особенностью процесса обучения робототехнике, электронике и инженерно-техническому творчеству является деятельность, основанная на практическом выполнении задач. Практический подход к профессиональному самоопределению отлично представлен через мероприятия движения World Skills Junior. Остается открытым вопрос об определении эффективности используемых организационных форм - очного и дистанционного обучения. Важно учитывать особенности, сильные и слабые стороны каждого формата взаимодействия для эффективного обеспечения непрерывности образовательной линии и процесса самоопределения обучающихся в условиях непредсказуемости современности.

Цель - определение педагогических условий формирования необходимых практических навыков у обучающихся при подготовке к соревнованиям Junior Skills через очную и дистанционную формы взаимодействия.

Материал и методы. С 2018 по 2020 г. на базе Детского центра образовательной робототехники Томского государственного педагогического университета и Курлекской средней общеобразовательной школы Томского района реализованы программы подготовки к соревнованиям Junior Skills. Подготовку прошли 75 обучающихся 3-6-х классов и 58 обучающихся 9-11-х классов. В исследовании были реализованы методы сравнительносопоставительного анализа, моделирования, наблюдение и опросные методы.

Результаты и обсуждение. В ходе проведения опытно-экспериментальной работы разработана и апробирована модель дистанционного формата реализации образовательной программы по подготовке обучающихся к соревнованиям профессионального мастерства уровня Junior Skills Russia, а также серия заданий по формированию первичных самостоятельных практико-ориентированных проб (по профилям робототехника, программирование, моделирование, электроника).

Заключение. Дистанционная форма образовательной программы добавляет в общий перечень мер подготовки к соревнованиям профессионального мастерства дополнительный опыт тренировки самоконтроля, выводит обучающихся из зоны комфорта и помогает научиться контролировать свой уровень стресса при работе в нестандартных условиях, дает возможность принимать ответственность за свои действия и позволяет самоопределиться с дальнейшим профессиональным профилем.
\end{abstract}

Ключевые слова: профессиональное самоорределение, дистанционная форма, Junior Skills, робототехника, электроника, педагогические условия.

\section{Введение}

Разнообразие взглядов на вопрос раннего профессионального самоопределения обучающихся школ говорит о том, что в целом этот процесс обозначается учеными [1-3] как поиск и нахождение личностного смысла в выбираемой, осваиваемой и уже выполняемой трудовой деятельности. От выпускников и обучающихся требуется четкая сформированность навыка самостоятельного выбора и готовности к овладению различными компетенциями на любом этапе своей жизни.

Согласно основным требованиям цифровой экономики будущего [1] профессиональные каче- ства выпускников учебных заведений должны отвечать следующим положениям:

- готовность к непрерывному самообразованию; боты;

- уверенный навык проектной и командной ра-

- формирование универсальных и практических компетенций в трудовой и бытовой сферах;

- междисциплинарный подход к реализации поставленных целей;

- совершенствование навыков применения информационно-коммуникационных технологий;

- уверенные навыки форсайтного (предсказывающего) мышления. 
Для того чтобы обеспечить обучающимся дополнительное время для самоопределения и коррекции своей образовательной траектории, уже в среднем звене школы важно начинать закладывать основные практические навыки за счет программ предпрофессионального обучения.

Актуальность создания и поддержки педагогических условий для раннего профессионального самоопределения в школах обусловлена необходимостью, вызванной стратегической потребностью экономики страны и общества в специалистах инженерно-технического профиля, способных практически применять свои знания в реальном мире $[4,5]$. Модель обучения ближайшего будущего должна учитывать тренды глобализации, автоматизации производств и роста конкуренции современного мира. Для обеспечения возможности построения индивидуальной образовательной траектории необходимо создать такие психолого-педагогические условия обучения, которые позволят обучающимся выйти за границы формальных учреждений и самостоятельно дать оценку требованиям, предъявляемым к успешному специалисту будущего. Такой подход к самоопределению и профессиональному становлению отражен в «Атласе будущих профессий», где описаны рекомендации и требования к освоению профессий будущего, и также можно увидеть практическую реализацию подхода через мероприятия движения World Skills Junior $[6,7]$.

Поскольку развитие информационных и отраслевых технологий позволяет рынку труда все время меняться, то на сегодняшний день ключевую роль в научно-техническом прогрессе играют электроника и робототехника. Обучение именно робототехнике и инженерно-техническим профилям на школьном этапе дает возможность формировать гибкую траекторию развития, закладывающую основы успешного освоения профессий будущего, поможет обучающимся овладеть навыком постоянно учиться.

Многие современные исследователи [8-11] данного вопроса отмечают перспективность такого подхода в образовании нового поколения, поскольку это будет способствовать повышению эффективности жизни и профессиональной самореализации в роботизированном и высокотехнологичном обществе. При этом если в будущем обучающийся (или члены его ближайшего окружения) не планирует профессионально заниматься робототехникой или становиться инженером, то роль этих технологий на общие сферы жизнедеятельности общества в целом (такие как медицина, сфера бытового обслуживания, финансовая безопасность и др.) с каждым годом будет лишь увеличиваться [8]. Это необходимо учитывать при построении своей профессиональной траектории. Многие зарубежные исследователи современности [12, 13] также обосновывают перспективность раннего вовлечения обучающихся в мир профессий посредством образовательной робототехники, компьютерной и электронной техники в силу мощной инструментальной составляющей этих направлений науки, которые сами по себя являются активаторами познавательных процессов и отправной точкой для формирования оптимальных условий для самоопределения.

Основной отличительной особенностью процесса обучения робототехнике, электронике и инженерно-техническому творчеству является то, что в их основе лежит деятельность, основанная на практическом выполнении задач, которые тесно связаны с жизненными ситуациями. Каждое занятие является практико-ориентированным. Именно поэтому интерес обучающихся к техническим наукам целесообразнее начинать через робототехнические профили с одновременным запуском процесса раннего профессионального самоопределения, а реализовать этот процесс через непосредственные профессиональные пробы. Профессиональные пробы являются одной из инновационных форм профессиональной ориентации школьников и во многом отличаются от традиционных форматов работы (например, тестирование или собеседование). Профессиональные пробы посредством робототехники и электроники помогут школьникам более точно и осознанно сформировать свои профессиональные интересы в поле инженерно-технического направления, а также понять, подходит ли им эта деятельность, своевременно скорректировать линию развития своих умений и навыков, понять, что именно их интересует [14].

Такой подход к раннему профессиональному образованию детей через профессиональные пробы хорошо представлен и реализован на чемпионатах уровня Junior Skills. Junior Skills - это образовательная программа ранней профориентации и формирования основ профессиональной подготовки, результаты которой участники демонстрируют в ходе соревнований по профессиональному мастерству [15]. Если рассмотреть профили «Мобильная робототехника» и «Электроника», то требования, предъявляемые стандартами Junior Skills по этим компетенциям, подразумевают применение участниками широкого диапазона soft skills и hard skills. Специалисты этих профессиональных областей занимаются проектированием устройств и систем, сборкой готовых прототипов, а также программируют и обслуживают механические, электрические и электронные системы. Кроме того, обязательным является выявление, анализ и устранение всех возможных неисправностей, слаженная работа в команде и грамотное обоснование своих решений. 
Для предоставления каждому школьнику возможности для раннего профессионального самоопределения через пробу себя в названных профессиональных сферах требуется разработка и реализация программ подготовки к мероприятиям Junior Skills [15]. Благодаря таким программам будет обеспечена дополнительная мотивация обучающихся к поиску альтернативных путей решения многих задач, проведению исследований и выполнение инженерно-робототехнических проектов с целью получения конкретных продуктов, которые можно самостоятельно измерить и проанализировать. Сегодня есть много образовательных продуктов, которые погружают в профильный предмет изучения или профессиональный трек. Широко распространена практика посещение музеев и центров научного творчества, кванториумов, комбинатов профессионального обучения и участие в различных соревновательных мероприятиях [16-18]. Поскольку цифровые технологии и дистанционные образовательные платформы все более интенсивно входят в нашу жизнь, то свободный доступ к этим ресурсам и платформам есть почти у всех.

Технологии позволяют обучающимся овладеть многими навыками, необходимыми для цифровых реалий завтрашнего дня, практически не покидая своего места нахождения. Но все же большинство обычных школ, особенно находящихся на определенном удалении от административных центров, продолжают испытывать разного рода дефициты в сфере реализации программ профессионального самоопределения (программы, методические рекомендации, кадровый состав и т. д.). Кроме того, очень часто обучающиеся не готовы использовать все предлагаемые цифровой средой возможности в полную силу, как правило, из-за низкой самоорганизованности, отвлекающих факторов цифрового мира или отсутствия координирующей помощи наставника. Очевидно, что цифровое пространство само по себе, с одной стороны, предлагает большие возможности для успешного самоопределения, а с другой - вносит определенные ограничения и риски [2]. Поэтому одним из приоритетных направлений обновления и дополнения контента информационной образовательной среды российских школ должно стать решение проблемы по созданию соответствующих педагогических условий для формирования непрерывности процесса профессиональной подготовки обучающихся. Одним из путей решения может стать подготовка к участию в соревнованиях Junior Skills через практические и профессиональные пробы.

Образовательная система России должна быть нацелена не только на поиск новых стратегически эффективных форматов обучения нового поколения, но и быть форсайтной, т. е. предсказывающей.
Понятие «педагогические условия» можно определить как «совокупность мер, направленных на повышение эффективности педагогической деятельности» $[19$, с. 8]. Поэтому важным видится процесс организации обучения таким образом, чтобы одинаково эффективно работать и в очной, и в дистанционной форме, тем самым всегда быть готовыми к любому развитию событий в мире в ближайшем будущем. Следует также учесть потенциальную возможность взаимозаменяемости очного и дистанционного форматов (в случае острой необходимости) и активного одновременного их применения. Это особенно актуально в условиях существующей действительности, связанной с ограничениями, вызванными реалиями пандемии и ограничительными мерами на посещение массовых мероприятий.

Само понятие «дистанционное обучение» законодательно закреплено в России. Согласно ст. 16 Федерального закона № 273-Ф3 «Об образовании в Российской Федерации» от 29.12.2012 под дистанционными образовательными технологиями понимаются образовательные технологии, реализуемые в основном с применением информационно-телекоммуникационных сетей при опосредованном (на расстоянии) взаимодействии обучающихся и педагогических работников [20].

Современные исследования в сфере применения формата дистанционного обучения в образовательных целях [21-23] ясно описывают основную классификацию моделей дистанционного обучения, которые строятся на основе практики и различаются между собой моделями образовательного взаимодействия между учениками, учителями и образовательными информационными объектами. Условия, создаваемые с помощью дистанционных технологий и систематизированных цифровых ресурсов, позволяют эффективно взаимодействовать всем участникам процесса, сводя к минимуму низкий уровень самоорганизации и потенциальные риски бесконтрольного пребывания обучающихся в сети.

Форма организации занятий через дистанционное взаимодействие в рамках образовательной программы по вовлечению обучающихся в процесс инженерно-технического творчества и подготовки к участию в соревновательных мероприятияx Junior Skills не только способствует организации непрерывности образовательного трека, но и дает вспомогательный материал для расширения базы теоретических знаний по профилям, позволяет практиковать самостоятельные практические пробы при выполнении круга заданий, очерченных педагогом. В случае очной формы работы у обучающихся появляется дополнительная возможность отрабатывать пропущенные уроки, наращивать 
свою ИКТ-грамотность, что является дополнительным инструментом мотивации к учебной деятельности.

Для создания наиболее оптимальных педагогических условий дистанционное обучение должно строиться с учетом всех перечисленных элементов, а также методов (синхронный и асинхронный) работы. Все вместе дает нам универсальный способ взаимодействия учителя с обучающимися. В итоге получается универсальный механизм, который позволяет общаться с широким кругом людей для поиска решения конкретных вопросов, способствует развитию обучающихся и росту профессиональных компетенций педагогов [23]. Все это расширяет возможности решения поставленных задач теоретической и практической направленности, обеспечиваемых за счет изучения робототехники и электроники посредством практических проб в профессиональном направлении. При сравнении взаимодействия дистанционного формата с очными формами происходит определенная трансформация педагогических условий, обеспечивающих эффективность процесса реализации образовательной программы практико-ориентированного направления.

Целью данной статьи является выявление трансформации педагогических условий формирования необходимых практических навыков при подготовки обучающихся к соревнованиям Junior Skills (при описании очного и дистанционного форматов программы).

Новизна дистанционной формы организации обучения по программе подготовки обучающихся через практические и профессиональные пробы состоит в интегрированном подходе к изучению электроники и мобильной робототехники отдельными блоками программы, позволяющими обучающимся скорректировать свое самоопределение после каждого этапа обучения и меньше зависеть от форм обучения, вовремя проводить коррекцию своей базы знаний. Поскольку сама по себе профессиональная проба подразумевает создание условий самостоятельности ее проведения, предлагаемые условия являются достаточными для того, чтобы сформировать у молодежи устойчивую мотивацию к непрерывности процесса самоопределения и профильной ориентации при выборе конкретной профессиональной деятельности [24].

Иначе говоря, процесс подготовки обучающихся к участию в соревновательных испытаниях по регламентам Junior Skills и их практические пробы становятся максимально осознанными, непрерывным, мотивированным, и что особенно важно процесс обучения и подготовки имеет системный характер. При возникновении ситуаций, требующих перехода обучающихся с очного формата об- учения на дистанционную форму программы подготовки, происходит:

- сохранение единой образовательной линии;

- минимизация временных потерь, возникающих при ожидании возобновления обычного (очного) режима посещения школы;

- исключение пропусков какого-либо информационного блока по изучаемой программе;

- компенсация отсутствия условий практической реализации некоторых проектов при нахождении обучающегося на режиме самоизоляции (по разным причинам).

\section{Материал и методы}

Реализация программы подготовки к соревнованиям Junior Skills начата в 2018 г. в очной форме, с сентября по ноябрь 2020 г. в соответствии с п. 7 распоряжения № 156-ра от 18.03.2020 (время действия режима «повышенная готовность») [25], отдельные блоки программы были реализованы через дистанционную форму организации с перспективой последующей реализации проектных замыслов на очных занятиях.

Развивающая направленность программы включает познавательно-исследовательские и изобразительно-конструкторские виды деятельности, которые первостепенно ориентированы на общее развитие способностей в сфере натурного моделирования с элементами робототехнических механизмов и содержит элементы ранней профориентации в инженерно-технической сфере через практическую реализацию возможностей и форм самовыражения обучающихся. С 2018 г. подготовку к соревнованиям в сфере профессионального самоопределения прошли 75 обучающихся 3-6-х классов и 58 обучающихся 9-11-х классов. Подготовка проходила в очном и дистанционном форматах.

Апробация дистанционной модели программы Junior Skills осуществлялась на базе двух площадок: «Детский центр образовательной робототехники» Томского государственного педагогического университета и «Курлекская средняя общеобразовательная школа» Томского района.

При проведении исследования использовались теоретические методы: анализ психолого-педагогической и методической литературы, технические характеристики робототехнических наборов и конструкторов по электронике, сравнительный анализ программных сред и дистанционных платформ взаимодействия, систематизация и обобщение фактов. В опытно-экспериментальной работе были реализованы анкетирование, наблюдение, анализ результатов опытно-экспериментальной работы.

Основываясь на опыте реализации программы «Электроника и мобильная робототехника» [26], была разработана и апробирована модель дистан- 
ционного формата реализации программы подготовки обучающихся к соревнованиям Junior Skills. Освоение материалов дистанционного блока образовательной программы осуществлялось как в синхронной, так и асинхронной форме.

Организация рефлексии собственной деятельности обучающихся представляет собой процедуру демонстрации и обоснования своих наработок в процессе дистанционного сеанса коммуникации с остальными участниками группы.

Для проведения сравнительного анализа педагогических условий очного и дистанционного формата программы, а также оценки практических и универсальных навыков, сформированных у обучающихся на начальном и завершающем этапах прохождения дистанционного блока программы, была использована разработанная и описанная ранее система измерительных мер.

\section{Результаты и обсуждение}

В ходе проведения опытно-экспериментальной работы была разработана и апробирована модель дистанционного формата реализации образовательной программы по подготовки обучающихся к соревнованиям профессионального мастерства уровня Junior Skills Russia, также серия заданий по формированию первичных самостоятельных практико-ориентированных проб у обучающихся в сфере профессионального профиля (робототехника, программирование, моделирование, электроника) через дистанционный формат взаимодействия.

Отличительной особенностью блока образовательной программы, транслируемой в дистанционной форме, является организация подготовки обучающихся к профессиональным пробам в сфере инженерно-технического направления в среде онлайн-симулятора по проектированию электронных устройств. Дистанционная форма организации обучения по программе подготовки позволяет мягко сочетать синхронный и асинхронный формат взаимодействия участников, что, в свою очередь, является одной из основ применения удаленных методов обучения [27].

Безусловно, центральное место в подготовке обучающихся к соревновательным мероприятиям по профессиональному мастерству (таких как Junior Skills, «Роботон-МиР» и др.) занимает синхронная форма обучения, которая подразумевает фиксированный график и время занятий с онлайнвзаимодействием всех участников образовательного процесса. В течение онлайн-занятия педагог получает возможность контактировать с группой обучающихся, включать необходимый контент для совместного обсуждения теоретических аспектов, необходимых для качественной и всесторонней подготовки к соревнованиям по профессиональным профилям. Также на онлайн-занятии осуществляется разбор практических задач в среде онлайн-симулятора, которые затем обучающиеся должны будут самостоятельно (асинхронно) выполнить и подготовить презентацию результатов своего труда в группе. Педагог может дать ссылки на вебинары, веб-конференции или иные образовательные ресурсы прокомментировать необходимый контент. При асинхронной форме взаимодействия обучающиеся не ограничены временем урока, занимаются в индивидуальном темпе. При необходимости они также могут получить дополнительные комментарии к выполняемому проекту или какие-либо материалы по средствам электронной почты или записей группы в социальных сетях. Асинхронное взаимодействие подразумевает деловую переписку по электронной или голосовой почте, обсуждение в чатах или на форуме, предоставление доступа к видеозаписям или актуальным ресурсам. Задания, выдаваемые обучающимся в рамках дистанционного формата обучения по программе, являются адаптированными вариантами заданий в соответствии с регламентами соревнований Junior Skills.

Объем теоретических знаний, предлагаемый к рассмотрению в дистанционной форме, является достаточным для организации самостоятельной практической работы обучающимися. Весь учебный материал связан с непосредственной реализацией каждого отдельного этапа моделирования, с описанием возможных неполадок и путей отладки, а также диагностикой каждого готового узла прототипа электронного или роботизированного устройства.

Анализ отечественной и зарубежной литературы $[9,11,12,14,28,29]$ позволил вывести одну из существенных характеристик понятия «компетенция» (один из главных параметров оценки в регламентах соревнований Junior Skills) - это умение решать настоящие практические задачи, основываясь на имеющихся знаниях и активно применяя сформированные навыки в деле. Именно по этой причине все задачи в рамках описываемой программы подготовки имеют практическую ориентацию и тесную взаимосвязь с жизненными процессами, требующими альтернативного способа решения.

Практическая ориентация была достигнута за счет интеграции методических принципов обучения робототехнике, электронике и основам инженерии. Использование в качестве учебного инструмента онлайнплатформы, программного обеспечения и элементной базы Arduino (Ардуино) [28, 29] дает возможность конструировать большое количество разнообразных электронных устройств и программировать их. Функциональная среда он- 
лайн-симулятора позволяет свободно проводить экспериментально-исследовательские лабораторные работы на компонентной базе, полностью совместимой с реальными наборами Arduino, тем самым стимулируя познавательную активность учащихся и процесс принятия ими самостоятельных осознанных решений. На основе знаний, полученных через теоретическую часть обучения и находясь под консультативным присмотром педагога, обучающиеся легко могут создавать различные автоматические и роботизированные устройства. Для организации практической деятельности «на дому» школьники используют необходимые радиокомпоненты и инструменты, расположенные в среде виртуального симулятора. При возвращении к очной форме занятий обучающиеся воспроизводят виртуальный прототип устройства на практике, используя реальные наборы по робототехнике и электронике.

Основными задачами программы, реализуемой через дистанционную форму организации обучения, стали:

- обобщение и закрепление знаний, полученных в различных образовательных областях (математика, физика, информатика, электроника, робототехника) через интеграцию в проект;

- мотивация к самообразованию и сохранение уровня вовлеченности обучающихся в процесс инженерного творчества;

- расширенное знакомство с современными и будущими профессиональными компетенциями на примере функциональных возможностей и сфер применения мобильной робототехники и электроники;

- отработка навыков решения конкретной практико-ориентированной задачи в соответствии с регламентами соревнований Junior Skills по указанным профилям;

- формирование системы знаний и умений, составляющих основное содержание программы в ее очной реализации;

- включение функциональных возможностей вычислительной платформы Arduino (Ардуино) в процесс самостоятельной разработки и программирования управляемых электронных устройств на базе.

Включение обучающихся в описанный формат деятельности позволяет расширить общетехнический кругозор и повысить культуру самостоятельности. Для мониторинга динамики результатов обучающихся практикуются следующие виды контроля:

- начальный контроль (вводное тестирование на определение сформированности soft skills, задания для определения уровня сформированности hard skills, общее собеседование);
- прогрессивный контроль (осуществляется по результатам выполнения учащимися практических заданий, по результатам креативности подхода к реализации проекта);

- итоговый контроль (защита итоговых проектов, личный вклад в совершенствование прототипа устройства, подготовка проекта для заявки на соревнования по профилю обучения).

Ключевые позиции при оценке выполнения контрольных заданий всех уровней, на которые делается акцент:

- качество сборки прототипа проектируемого мобильного робота или устройства;

- качество монтажа электронных компонентов и оформление общего вида проекта;

- моделирование и конструирование основных и сопутствующих конструкций;

- программирование в среде Lego Mindstorms $\mathrm{EV} 3$ и $\mathrm{C} / \mathrm{C}++$ (язык устройств Arduino);

- уровень использования компьютера в качестве инструмента для проектирования электронных схем, разводки печатных плат, программирования встроенных устройств, поиска информации;

- качество ведения технического журнала, уровень представления и защиты проекта на контрольных занятиях.

Анализа данных, полученных в результате апробации дистанционной и очной форм подготовки обучающихся к соревнования профессионального мастерства по профилям мобильная робототехника и электроника, позволил определить и выделить педагогические условия, необходимые для формирования оптимальной информационной среды для раннего профессионального самоопределения обучающихся в сфере инженерно-технического профиля. Результаты обработки данных представлены в таблице.

Из таблицы видно, что уровень требований к организации части педагогических условий при проведении очного и дистанционного формата образовательной программы является разным. В первую очередь это зависит от активности применения средств информационных и коммуникационных технологий в образовательном процессе и количества заданий для самостоятельного выполнения обучающимися

Для подтверждения эффективности проведенной работы были проведены контрольные замеры изменения уровня знаний в рамках изучаемого блока образовательной программы. Анализ данных показал, что в результате освоения блока программы, реализованной в дистанционном форме, обучающимися были достигнуты следующие результаты:

- углубление теоретической базы знаний основ электроники и робототехники в рамках заданного образовательного блока; 
Борисова В. А. Реализация программ подготовки к соревнованиям Junior Skills: очная и дистанционная...

Сравнение педагогических условий при очной и дистанщионной форме организации занятий, их влияние на уровень знаний обучающихся (в пределах блока образовательной программы, адаптированной для дистаничионого формата)

\begin{tabular}{|c|c|c|}
\hline \multirow{2}{*}{ Педагогическое условие } & \multicolumn{2}{|c|}{ Уровень обеспечения } \\
\hline & Очная форма & Дистанционная форма \\
\hline Необходимость непрерывного самообразования & Средний & Высокий \\
\hline $\begin{array}{l}\text { Наличие дополнительной учебно-познавательной деятельности, направленной } \\
\text { на формирование профессиональных компетенций (с учетом индивидуальных } \\
\text { особенностей каждого) }\end{array}$ & Высокий & Высокий \\
\hline $\begin{array}{l}\text { Адаптация заданий (проектов), направленных на формирование первичных } \\
\text { самостоятельных практико-ориентированных проб }\end{array}$ & Высокая & Средняя \\
\hline $\begin{array}{l}\text { Практико-ориентированная направленность учебного процесса с получением } \\
\text { реального прототипа проекта }\end{array}$ & Средний & Высокий \\
\hline $\begin{array}{l}\text { Наличие системы мониторинга результатов деятельности на всех этапах } \\
\text { программы }\end{array}$ & Высокий & Высокий \\
\hline $\begin{array}{l}\text { Наличие системы мониторинга результатов деятельности на каждом занятии } \\
\text { по программе }\end{array}$ & Высокий & Низкий \\
\hline Непрерывное взаимодействие участников внутри группы & Низкий & Средний \\
\hline $\begin{array}{l}\text { Осуществление систематической работы по формированию профессиональных } \\
\text { компетенций }\end{array}$ & Средний & Высокий \\
\hline Обеспечение информационной безопасности обучающихся & Высокий & Средний \\
\hline $\begin{array}{l}\text { Включение дополнительных компонентов образовательной деятельности } \\
\text { (стабильное подключение к сети Интернет, допуск к онлайн-платформам, } \\
\text { доступное программное обеспечение, ссылки на дидактические материалы) }\end{array}$ & Высокий & Низкий \\
\hline Обеспечение оптимального уровня стресса на занятии & Высокий & Средний \\
\hline Соответствие временному лимиту занятия & Высокий & Средний \\
\hline Свободный доступ к цифровым источникам дополнительной информации & Высокий & Низкий \\
\hline $\begin{array}{l}\text { Обеспечение условий для командного взаимодействия и проявления лидерских } \\
\text { качеств }\end{array}$ & Низкий & Высокий \\
\hline Ответственность за итоговый результат & Высокий & Высокий \\
\hline Планирование этапов деятельности & Высокий & Средний \\
\hline Творчество и проявление фантазии в реализации (представлении) проекта & Средний & Высокий \\
\hline
\end{tabular}

- наработка навыка чтения, понимания и составления электрических принципиальных схем согласно регламентам Junior Skills;

- закрепление знаний по основным свойствам, характеристикам и области применения изученных компонентов электроники (резисторы, конденсаторы, диоды, стабилитроны, транзисторы, микросхемы);

- получение представления о современной элементной базе электроники и их функциональных возможностях;

- закрепление знаний по технике безопасности при работе с электричеством, освоение правил пользования специализированным инструментом, необходимом при практической реализации проектов;

- освоение требуемого программного обеспечения, используемого при программировании устройств и работе в среде онлайн-симуляторе;

- практика разработки программ, анализ кода и внесение необходимых корректив;

- владение способами и методами конструирования отдельных деталей мобильных робототехнических систем;
- отработка навыка слаженного группового взаимодействия.

Сама программа подготовки является вариативной, что способствует формированию разновозрастных групп и возможности самостоятельного выбора траектории своего образования и развития каждым обучающимся в разрезе интересуемого профиля.

К возможным рискам применения дистанционной формы подготовки обучающихся к практическим пробам по регламентам Junior Skills можно отнести:

- снижение эффективности активных методов активизации и вовлечения обучающихся в образовательный процесс;

- перенос акцента на коллективную мотивацию для исключения ситуации конфликтов и разрозненности уровня знаний в группе;

- выделение отдельного времени урока для обязательного и открытого подведения итогов урока с поощрением каждого ученика, положительно проявившего себя в процессе взаимодействия;

- дополнительное стимулирование всех участников процесса к непрерывности познания новых 
профессиональных треков, необходимых для достижения успехов в практической реализации своих умений;

- применение специальных методов оценки результативности обучающихся на уроке и в процессе самостоятельного обучения;

- отсутствие живого общения с педагогом может вызывать беспокойство у обучающихся, потерю образовательных ориентиров;

- возможное снижение уровня ответственности и организованности у некоторых обучающихся;

- негативное влияние компьютерной техники на общее состояние здоровья человека.

\section{Заключение}

Дистанционная форма образовательной программы добавляет в общий перечень мер подготовки к соревнованиям профессионального мастерства дополнительный опыт тренировки самоконтро- ля, выводит обучающихся из зоны комфорта и помогает научиться контролировать свой уровень стресса при работе в нестандартных условиях, дает возможность принимать ответственность за собственные действия, тем самым расширяет потенциальные возможности каждого.

Работа в дистанционном режиме предусматривает выстраивание каждым обучающимся собственного индивидуального темпа работы, поскольку онлайн-формат взаимодействия подразумевает обязательный асинхронный режим взаимодействия, дающий возможность каждому обучающемуся тщательно проработать необходимый теоретический и практический материал для выполнения определенного этапа проектирования. Кроме того, у каждого обучающегося появляется возможность получения прототипа устройства с авторским дизайном в силу появления большего количества времени (работа дома) на самовыражение своей креативности.

\section{Список литературы}

1. Лебедева Е. В. Сопровождение профессионального самоопределения обучающихся в условиях цифровизации // Профессиональное образование и рынок труда. 2019. № 2. С. 49.

2. Самсоненко Л. С. Психологические особенности профессионального самоопределения личности в цифровом мире // Мотивирующая цифровая среда как тренд современного образования. Оренбург: ОГПУ, 2019. С. 173-184.

3. Пряжников Н. С. Профессиональное самоопределение: теория и практика. М.: Академия, 2007. 320 с.

4. Перечень поручений по реализации Послания Президента Федеральному Собранию от 3 декабря 2015 г. Пр-2508, п. 1.16 // Поручения Президента. URL: http://kremlin.ru/acts/assignments/orders/50899 (дата обращения: 10.02.2021).

5. Федеральный закон РФ от 29.09.2012 № 273-Ф3 «Об образовании в РФ». - Инновационная стратегия Томской области до 2030 года. URL: http://www.consultant.ru/document/cons_doc_LAW_140174/a9a28ae49b86df0327132598d1e9b42bffda4ab6/ (дата обращения: 10.02.2021).

6. Атлас новых профессий 3.0 / под ред. Д. Варламовой, Д. Судакова. М.: Интеллектуальная литература, 2020. 456 с. URL: https://new.atlas100.ru/ (дата обращения: 10.02.2021).

7. Официальный сайт World Skills Russia // О программе Junior Skills. URL: https://worldskills.ru/final/naczionalnyij-final/ juniorskills.html (дата обращения: 17.02.2021).

8. Седина Е. С., Соболева Е. В. Обоснование необходимости совершенствования модели обучения робототехнике как основы стратегии подготовки кадров для профессий будущего // Научно-методический электронный журнал «Концепт». 2018. № 7. C. 540-551. URL: http://e-koncept.ru/2018/181046.htm (дата обращения: 17.02.2021).

9. Скурихина Ю. А. Методические принципы изучения робототехники в рамках урочной и внеурочной деятельности // Научно-методический электронный журнал «Концепт». 2018. № 4. С. 223-233. URL: http://e-koncept.ru/2018/181020.htm (дата обращения: 17.02.2021).

10. Караваев Н. Л., Соболева Е. В., Вотинцева М. Л. Совершенствование сквозного курса робототехники для подготовки специалистов профессий будущего // Научно-методический электронный журнал «Концепт». 2019. № 3. C. 44-58. URL: http://e-koncept.ru/2019/191022.htm (дата обращения: 17.02.2021)

11. Kim J.-O., Kim J. Development and Application of Art Based STEAM Education Program Using Educational Robot// International Journal of Mobile and Blended Learning. 2018. № 3. P. 46-57.

12. Jonassen D. H. Computers as mindtools for schools. Prentice Hall, 2006. 253 p.

13. Технология 8 класс: учеб. для учащихся общеобразоват. организаций / Н. В. Матяш, А. А. Электов, В. Д. Симоненко и др. 2-е изд., перераб. М.: Вентана-Граф, 2016. 208 с.

14. Белоусов А. А., Некрасова Г. Н. Проектирование системы профессиональных проб для школьников // Научно-методологический электронный журнал «Концепт». 2018. № 10. С. 899-912.

15. Абакумова Н. Н., Борисова В. А. Механизмы реализации и этапы развития Junior Skills как перспективной программы раннего профессионального самоопределения обучающихся // Вестн. Томского гос. ун-та. 2019. № 446. С. 170-177.

16. Робот-бабочка - образовательная платформа для подготовки инженеров // Roboticum. URL: http://robotics-spb.ru/education/ (дата обращения: 03.02.2021). 
17. Сбербанк поддержал чемпионат ЕВРОБОТ // Занимательная робототехника. URL: https://www.sberbank.ru/ru/press_center/ all/article?newsID=ddd8469d-d74c-42df-8394-62c1052f10da\&blockID=1303\&regionID=77\&lang=ru\&type=NEWS (дата обращения: 03.02.2021).

18. Турнир молодых профессионалов «ТеМП» // Росатом. URL: https://rosatom.ru/career/obrazovanie/turnir-molodykhprofessionalov-temp/ (дата обращения: 03.02.2021).

19. Ипполитова Н. В., Стерхова Н. С. Анализ понятия «педагогические условия»: сущность, классификация // General and Professional Education. 2012. № 1. C. 8-14.

20. Об образовании в Российской Федерации: Федеральный закон Российской Федерации от 29.12.2012 № 273-Ф3 // Справочно-правовая система «Консультант Плюс». URL: http://base.consultant.ru/cons/cgi/online.cgi?req=doc;base=LAW;n=1584 29; dst=0 (дата обращения: 03.02.2021).

21. Снегурова В. И. Модели дистанционного обучения в системе среднего образования // Вестн. Российского ун-та дружбы народов. Серия: Информатизация образования. 2009. № 2. С. 106-120.

22. Хуторской А. В. Современная дидактика: учеб. для вузов. СПб.: Питер, 2001. 639 с.

23. Абдуллаев Д. А., Муцурова 3. М. Организация дистанционного обучения в школе // Мир науки, культуры, образования. 2019. № 3 (76). С. 168-169.

24. Можаров М. С., Читайло К. С. Разработка профессиональных проб по 3D моделированию для старших классов // Современное педагогическое образование. Самара, 2020. С. 81-85.

25. Официальный интернет-портал Администрации Томской области. О внесении изменений в распоряжение Администрации Томской области от 18.03.2020 № 156-pa. URL: https://www.tomsk.gov.ru/uploads/ckfinder/1/userfiles/ files/\%D0\%A052\%D0\%B0.pdf (дата обращения: 17.02.2021).

26. Борисова В. А. Интегрированная программа изучения электроники и мобильной робототехники как первая ступень в подготовке обучающихся к соревнованиям Junior Skills // Психолого-педагогическое сопровождение образовательного процесса: сб. тр. / под ред. А. В. Хитровой. Изд-во Типография «Ариал», 2020. С. 332-337.

27. Вознесенская Е. В. Дистанционное обучение - история развития и современные тенденции в образовательном пространстве // Наука и школа. 2017. № 1. С. 116-123.

28. Белов А. В. Arduino: от азов программирования до создания практических устройств. СПб.: Наука и техника, 2018.480 с.

29. Блум Д. Изучаем Arduino: инструменты и методы технического волшебства: пер. с англ. СПб.: БХВ-Петербург, 2019. $336 \mathrm{c}$.

Борисова Виктория Анатольевна, аспирант, Национальный исследовательский Томский государственный университет (пр. Ленина, 36, Томск, Россия, 634050).

E-mail: kitnessev@gmail.com

Материал поступил в редакциию 17.03.2021

DOI 10.23951/1609-624X-2021-5-105-115

\section{IMPLEMENTATION OF TRAINING PROGRAMS FOR THE JUNIOR SKILLS COMPETITION: TRADITIONAL CLASSROOM AND REMOTE LEARNING FORMATS}

\section{A. Borisova}

National Research Tomsk State University, Tomsk, Russian Federation

Introduction. Preparing schoolchildren for participation in JuniorSkills competitions is an urgent task of modern education. A feature of the process of teaching robotics, electronics and engineering and technical creativity is activities based on the practical implementation of tasks. A hands-on approach to professional self-determination is well presented through the events of the World Skills Junior movement. The question of determining the effectiveness of the organizational forms used in face-to-face and remote learning remains open. It is important to take into account the peculiarities, strengths and weaknesses of each format of interaction. It is important for effectively ensuring the continuity of the educational line and the process of self-determination of students in the conditions of the unpredictability of our time.

Aim and objectives. Determination of the pedagogical conditions for the formation of the necessary practical skills among schoolchildren in preparation for the Junior Skills competition through face-to-face and remote forms of interaction.

Material and methods. The distance model of the Junior Skills program was tested on the basis of two sites: The Children's Center for Educational Robotics of the Tomsk State Pedagogical University and the Kurlek Secondary School of the Tomsk District. Since 2018, 75 students in grades 3-6 and 58 students in grades 9-11 have been prepared for competitions in the field of professional self-determination. The training took place in face-to-face and remote formats. 
Results and discussion. In the course of the experimental work, a model of the distance format for the implementation of the educational program for the preparation of schoolchildren for competitions of professional skills of the Junior Skills Russia level was developed and tested. A series of tasks has been developed for the formation of primary independent practice-oriented tests (for the profiles of robotics, programming, modeling, electronics).

Conclusion. The remote form of the educational program adds additional experience of self-control training to the general list of preparation measures for professional skill competitions. It takes schoolchildren out of their comfort zone and helps them learn to control their stress levels when working in non-standard conditions. Also, it gives the opportunity to take responsibility for their actions and allows self-determination with a further professional profile.

Keywords: professional self-determination, remote learning, Junior Skills, robotics, electronics, pedagogical conditions.

\section{References}

1. Lebedeva E. V. Soprovozhdeniye profesional'nogo samoopredeleniya obychaushchikhsya v usloviyakh tsifrovizazii [Support for the professional self-determination of students in the context of digitalization]. Professional'noye obrazovaniye $i$ rynok truda, 2019, no. 2, p. 49 (in Russian).

2. Samsonenko L. S. Psikhologicheskiye osobennosti professional'nogo samoopredeleniya lichnosti v tsifrovom mire [Psychological features of professional self-determination of personality in the digital world]. Motiviruyushchaya tsifrovaya sreda kak trend sovremennogo obrazovaniya [Motivating digital environment as a trend in modern education]. Orenburg, OGPU Publ., 2019. pp. 173-184 (in Russian).

3. Pryazhnikov N. S. Professional'noye samoopredeleniye: teoriya i praktika [Professional self-determination: theory and practice]. Moscow, Akademiya Publ., 2007. 320 p. (in Russian).

4. Perechen' porucheniy po realizatsii Poslaniya Prezidenta Federal'nomu Sobraniyu ot 3 dekabrya 2015. Pr-2508, p. 1.16 [The list of instructions for the implementation of the President's Address to the Federal Assembly of December 3, 2015 Pr-2508]. Porucheniya Prezidenta [President's assignments] (in Russian). URL: http://kremlin.ru/acts/assignments/orders/50899 (accessed 10 February 2021).

5. Federal'nyy zakon RF ot 29.09.2012 № 273-FZ “Ob obrazovanii v RF” - Innovatsionnaya strategiya Tomskoy oblasti do 2030 goda [Innovation strategy of the Tomsk region until 2030] (in Russian). URL: http://www.consultant.ru/document/cons_doc_ LAW_140174/a9a28ae49b86df0327132598d1e9b42bffda4ab6/ (accessed 10 February 2021).

6. Atlas novykh professiy 3.0. Pod redaktsiyey D. Varlamovoy, D. Sudakova [Atlas of new professions. Edited by D. Varlamova, D. Sudakov]. Moscow, Intellektual'naya Literatura Publ., 2020. 456 p. (in Russian). URL: https://new.atlas100.ru/ (accessed 10 February 2021).

7. Ofitsial'nyy sayt World Skills Russia [World Skills Russia official website]. O programme Junior Skills [About Junior Skills program] (in Russian). URL: https://worldskills.ru/final/naczionalnyij-final/juniorskills.html (accessed 17 February 2021).

8. Sedina E. S., Soboleva E. V. Obosnovaniye neobkhodimosti sovershenstvovaniya modeli obucheniya robototekhnike kak osnovy strategii podgotovki kadrov dlya professiy budushchego [Justification of the need to improve the model of teaching robotics as the basis of the strategy for training personnel for the professions of the future]. Nauchno-metodicheskiy elektronnyy zhurnal “Kontsept”, 2018, no. 7, pp. 540-551 (in Russian). URL: http://e-koncept.ru/2018/181046.htm (accessed 17 February 2021).

9. Skurikhina Yu. A. Metodicheskiye printsipy izucheniya robototekhniki v ramkakh urochnoy i vneurochnoy deyatel'nosti [Methodological principles of studying robotics in the framework of lesson and extracurricular activities]. Nauchno-metodicheskiy elektronnyy zhurnal «Kontsept», 2018, no. 4, pp. $223-233$ (in Russian). URL: http://e-koncept.ru/2018/181020.htm (accessed 17 February 2021).

10. Karavayev N. L., Soboleva E. V., Votintseva M. L. Sovershenstvovaniye skvoznogo kursa robototekhniki dlya podgotovki spetsialistov professiy budushchego [Improving the end-to-end robotics course to train professionals for the professions of the future]. Nauchno-metodicheskiy elektronnyy zhurnal "Kontsept", 2019, no. 3, pp. 44-58 (in Russian). URL: http://e-koncept. ru/2019/191022.htm (accessed 17 February 2021).

11. Kim J.-O., Kim J. Development and Application of Art Based STEAM Education Program Using Educational Robot. International Journal of Mobile and Blended Learning, 2018, no. 3, pp. 46-57.

12. Jonassen D. H. Computers as mindtools for schools. Prentice Hall, 2006. 253 p.

13. Matyash N. V., Elektov A. A., Simonenko V. D. et al. Tekhnologiya 8 klass: uchebnik dlya uchashchikhsya obshcheobrazovatel'nykh organizatsiy [Technology grade 8: textbook for students of general education organization]. Moscow, Ventana-Graf Publ., 2016. 208 p. (in Russian).

14. Belousov A. A., Nekrasova G. N. Proektirovaniye sistemy professional'nykh prob dlya shkol'nikov [Designing a professional testing system for schoolchildren]. Nauchno-metodologicheskiy elektronnyy zhurnal "Kontsept", 2018, no. 10, pp. 899-912 (in Russian).

15. Abakumova N. N., Borisova V. A. Mekhanizmy realizatsii i etapy razvitiya Junior Skills kak perspektivnoy programmy rannego professional'nogo samoopredeleniya obuchayushchikhsya [Implementation mechanisms and stages of development of Junior Skills as a promising program for early professional self-determination of students]. Vestnik Tomskogo gosudarstvennogo universiteta - Tomsk State University Journal, 2019, no. 446, pp. 170-177 (in Russian). 
16. Robot-babochka - obrazovatel'naya platforma dlya podgotovki inzhenerov [Butterfly robot - educational platform for training engineers]. Roboticum (in Russian). URL: http://robotics-spb.ru/education/ (accessed 3 February 2021).

17. Sberbank podderzhal chempionat EVROBOT [Sberbank Supported the EUROBOT Championship]. Zanimatel'naya robototekhnika [Entertaining Robotics] (in Russian). URL: https://www.sberbank.ru/ru/press_center/all/article?newsID=ddd8469d-d74c42df-8394-62c1052f10da\&blockID=1303\&regionID=77\&lang=ru\&type=NEWS (accessed 3 February 2021).

18. Turnir molodykh professionalov "TeMP”. Rosatom (in Russian). URL: https://rosatom.ru/career/obrazovanie/turnir-molodykhprofessionalov-temp/ (accessed 3 February 2021).

19. Ippolitova N. V., Sterkhova N. S. Analiz ponyatiya "pedagogicheskiye usloviya": sushchnost', klassifikatsiya [Analysis of the concept of "pedagogical conditions": essence, classification]. General and Professional Education, 2012, no. 1, pp. 8-14 (in Russian).

20. Ob obrazovanii v Rossiyskoy Federatsii: Federal’nyy zakon Rossiyskoy Federatsii ot 29.12.2012 № 273-FZ [About education in the Russian Federation]. Spravochno-pravovaya sistema "Konsul 'tant Plyus" [Reference and legal system "Consultant Plus"] (in Russian). URL: http://base.consultant.ru/cons/cgi/online.cgi?req=doc;base=LAW;n=158429;dst=0 (accessed 3 February 2021).

21. Snegurova V. I. Modeli distantsionnogo obucheniya v sisteme srednego obrazovaniya [Distance learning models in the secondary education system]. Vestnik Rossiyskogo universiteta druzhby narodov. Seriya: Informatizatsiya obrazovaniya - RUDN Journal of Informatization in Education, 2009, no. 2, pp. 106-120 (in Russian).

22. Khutorskoy A.V. Sovremennaya didaktika: Uchebnik dlya vuzov [Modern Didactics: A Textbook for Universities]. Saint Petersburg, Piter Publ., 2001. 639 p. (in Russian).

23. Abdullayev D. A., Mutsurova Z. M. Organizatsiya distantsionnogo obucheniya v shkole [Organization of distance learning at school]. Mir nauki, kul tury, obrazovaniya - The world of science, culture and education, 2019, no. 3 (76), pp. $168-169$ (in Russian).

24. Mozharov M. S., Chitaylo K. S. Razrabotka professional'nykh prob po 3D modelirovaniyu dlya starshikh klassov [Development of professional samples for 3D modeling for senior classes]. Sovremennoye pedagogicheskoye obrazovaniye - Modern Pedagogical Education, 2020, no. 12, pp. 81-85 (in Russian).

25. Ofitsial'nyy internet-portal Administratsii Tomskoy oblasti. O vnesenii izmeneniy v rasporyazheniye Administratsii Tomskoy oblasti ot 18.03.2020 № 156-ra [The official Internet portal of the Tomsk Region Administration. On amendments to the order of the Administration of the Tomsk Region dated 18.03.2020 No. 156-ra] (in Russian). URL: https://www.tomsk.gov.ru/uploads/ckfinder/1/userfiles/files/\%D0\%A052\%D0\%B0.pdf (accessed 17 February 2021).

26. Borisova V. A. Integrirovannaya programma izucheniya elektroniki i mobil'noy robototekhniki kak pervaya stupen' v podgotovke obuchayushchihsya k sorevnovaniyam Junior Skills [An integrated program for the study of electronics and mobile robotics as the first step in preparing students for the Junior Skills competition]. Psikhologo-pedagogicheskoye soprovozhdeniye obrazovatel'nogo protsessa: Sbornik trudov [Psychological and pedagogical support of the educational process: collection of works]. Edited by A. V. Khitrova. Izdatel'stvo Tipografiya “Arial” Publ., 2020. Pp. 332-337 (in Russian).

27. Voznesenskaya E. V. Distantsionnoye obucheniye - istoriya razvitiya i sovremennye tendentsii v obrazovatel'nom prostranstve [Distance learning - history of development and current trends in the educational space]. Nauka i shkola - Science and School, 2017, no. 1, pp. 116-123 (in Russian).

28. Belov A. V. Arduino: ot azov programmirovaniya do sozdaniya prakticheskih ustroystv [Arduino: from the basics of programming to creating practical devices]. Saint Petersburg, Nauka i tekhnika Publ., 2018. 480 p. (in Russian).

29. Blum D. Izuchayem Arduino: instrumenty i metody tekhnicheskogo volshebstva: Perevod s angliyskogo [Arduino: tools and techniques for technical magic. Translation from English]. Saint Petersburg, BKHV-Peterburg Publ., 2019. 336 p. (in Russian).

Borisova V. A., postgraduate student, National Research Tomsk State University (pr. Lenina, 36, Tomsk,

Russian Federation, 634050).

E-mail:kitnessev@gmail.com 